\title{
Economic Situation in Tunisia and Resilience Strategies in Times of Covid-19 and Beyond
}

\author{
Syrine Ben Romdhane* \\ Department of Finance and Accounting, High Institute of Management, University of Tunis, Tunisia
}

*Corresponding Author: Syrine Ben Romdhane, Department of Finance and Accounting, High Institute of Management, University of Tunis, Tunisia

\begin{abstract}
At the start of 2020, the sudden outbreak of the coronavirus pandemic struck a blow to the development of the economy worldwide. Its spread has had a dual effect: a direct impact on production volumes globally on the one hand, and disruptions and alterations in supply and distribution chains on the other. In Tunisia, a myriad of initiatives and accomplishments with as much skill and sensitiveness have been deployed and well implemented since the start of the epidemic. In this short report, we first focus on the impact of Covid-19 on global and Tunisian economic situations, and then we are interested in the reforms undertaken by the Tunisian state for a more efficient and reinforced health system. Just after, we list the strategic actions adopted by Tunisia to generate investment results in a challenging environment post Covid19. Finally, we study which sectors of the Tunisian economy investors should be looking at in the aftermath of Covid-19.
\end{abstract}

Keywords: Coronavirus pandemic, Tunisian state, economic situation, investments, FDI, technology.

\section{INTRODUCTION}

Tunisia's potential has long been acknowledged. The country upholds a plethora of undeniable structural and strategic assets, stemming inter alia from its historical openness, its geographical location allowing it to be very close to a huge European market and serving as a hub for world powers, and its cheap qualified, responsive and multidisciplinary workforce which undoubtedly embodies the essence of its competitiveness on a global scale.

Last but not least: the country has a multidimensional economy and modular industrial structures adapted to the rapidly changing international requirements. Its efficiency-driven approach allows Tunisia to consolidate its integration at the heart of global value chains.

The sudden coronavirus outbreak put the spotlight on an even more significant asset. Indeed, and as an old French proverb says "There is something good in everything bad"; Sources of innovation and genius have flourished massively all over Tunisia since the beginning of the crisis and have revealed young Tunisians of exceptional level: scientists of great value, high-caliber doctors and health personnel, world-class engineers, not to mention creative and talented start uppers.

In this short report, we first focus on the impact of Covid-19 on global and Tunisian economic situations, and then we are interested in the reforms undertaken by the Tunisian state for a more efficient and reinforced health system. Just after, we list the strategic actions adopted by Tunisia to generate investment results in a challenging environment post Covid-19. Finally, we study which sectors of the Tunisian economy investors should be looking at in the aftermath of Covid-19

\section{Covid-19 and Global and Tunisian Economic Situations: Review of the First QUARTER OF 2020}

\subsection{Global Economic Situation}

The reign of uncertainty over the course of the pandemic makes global growth forecasts in turn extremely uncertain. These depend on several factors the interaction of which is difficult to predict, including the intensity and effectiveness of containment measures, the extent of supply disruptions, the impact of the dramatic tightening in global financial conditions, the changes in usual spending patterns etc. 
Faced with this formidable enemy that is the coronavirus, many countries are stumbling upon internal constraints that limit their growth potential: health shock, internal economic disruptions fall in external demand, reversals in capital flows and collapse in commodity prices.

According to the latest IMF estimates, growth prospects are disappointing in both developed and emerging countries. It will cost the world economy $3 / 4$ growth points in 2020 , mainly due to the lockdown imposed on more than 3 billion inhabitants and the closure of borders. As a result, global growth forecasts dropped from 3.4\% at the start of 2019 to 2.6\% at the start of March 2020, leading to a decline of $3 \%$ in mid-April 2020. Thus, it seems increasingly clear that the risks of a worsening situation predominate and global growth is far from returning to pre-pandemic levels.

On the other hand, an overview of the main countries shows that China, one of the largest workshops in the world and the first stage in global value chains for various manufacturing activities such as the automobile industry (a branch that is now affected) or the drug industry (a branch that is under the pressure of increased demand) reported a decline of about 7\% of its GDP, in the first quarter of 2020 when the country was paralyzed by COVID-19 pandemic.

The so-called BRICS countries - Brazil, Russia, India, China, and South Africa - have suffered significant economic collapse. In these countries, contractions were severe ranging from $7.7 \%$, in South Africa, to $11 \%$ in Brazil. This contraction will improve slightly in the second quarter, since it is expected that the decline will be of "only" 9.3\%.

The OECD area, meanwhile, remains mired in recession. It recorded a 1.8\% decline in real GDP in the first quarter of 2020, the largest drop since the $2.3 \%$ contraction in the first quarter of 2009 . Among the seven major economies, although growth is holding up in Germany, activity continues to stagnate in France, where the lockdown measures were the most stringent and implemented earlier, and is contracting particularly in countries in difficulty such as Italy, Spain, Portugal and Greece.

Emerging and developing economies, for their part, are being held back by the slowdown and paralysis of the economies in advanced countries, but also by the difficulties in overcoming internal obstacles to growth.

The magnitude of the pandemic in the United States and Japan explains the weak recovery, which is unusual in the history of the American and Japanese economic cycles. However, growth has been highly heterogeneous and torn between the dynamism of emerging countries, the resistance of the United States and the persistent decline in the euro zone. When it comes to the United States and Japan, there is a burst of optimism. Indeed, the growth recorded during this first quarter of 2020 was driven by an ambitious fiscal stimulus plan and a sharp decline in the dollar and the yen. Their economies have been supported by an upswing in real estate, manufacturing, stock exchange and employment markets.

In addition, in terms of global FDI flows, and all other factors being equal, the epidemic caused them to decline fairly during the first quarter of 2020, reducing their annual growth forecasts from $-5 \%$ to $15 \%$, according to UNCTAD. The decline in foreign investment is particularly felt in the country's most affected by the epidemic. And it is likely that the FDI record will remain gloomy in the coming months. Indeed, and in the wake of the coronavirus pandemic, UNCTAD predicted a global reduction in foreign investment of around 40\% for the period 2020-2021.

\subsection{Tunisian Economic Situation}

As far as Tunisia is concerned, let us recall, first of all, that during the two months preceding the pandemic (January and February 2020), the Tunisian economy was operating normally and some signs of improvement in the business climate began to be observed following the good tourist season. Likewise, indicators show that net foreign currency assets exceeded the equivalent of 110 days in February 2020, headline inflation continued to fall to 5.8\% against $6.1 \%$ observed in December 2019 and $6,7 \%$ in February 2019. In addition, the dinar continued its tendency to appreciate against the euro where 1 euro was worth 3.118 dinars at the end of February 2020 against 3.465 in February 2019. The trade balance deficit improved slightly, from $2462 \mathrm{MD}$ at the end of February 2019 to $2319 \mathrm{MD}$ during the first two months of 2020 (i.e. a gain of $144 \mathrm{MD}$ ). This result was achieved despite the slight drop in exports at the end of February $2020(-1.5 \%)$ and would therefore amount to an even greater drop in national imports $(-2.5 \%)$. 
Mainly, in mid-March 2020, and like other countries around the world, Tunisia was not spared by the spread of the coronavirus. As mentioned above, its magnitude is difficult to predict, but its negative impact on the national economy was prominently felt. Indeed, in the first quarter of 2020, the real GDP decreased by $1.7 \%$ compared to the same quarter of 2019 and by $2 \%$ compared to the fourth quarter of 2019, according to the National Institute of Statistics. This drop is due in particular to the lockdown that was implemented since mid-March to contain the coronavirus epidemic.

According to the "Global Economic Prospects" report (to be published in May 2020), Tunisia's GDP growth is projected at $-4.3 \%$. For its part, the IMF talks about $-3.4 \%$, which represents the greatest recession in the history of Tunisia since its independence (In 2011, the year of the revolution, growth fell by $1.9 \%$. Today, it doubled!). This forecast obviously remains dependent on the absence of a second pandemic wave in the country.

Another unexpected but predictable fact, the flow of foreign investments registered a decline of around $24.1 \%$ in the first quarter of 2020 compared to that of 2019 , with only 461.7 million dinars that were invested in Tunisia in the first quarter against 608.2 million dinars the previous year. This kickback is generated by the drop in Direct Investments to $-23.8 \%$, declining from 603.7 to 459.8 million dinars, as well as by the contraction of portfolio investments by $-58.2 \%$, dropping from 4.6 to 1.9 million dinars.

The table below shows the variations of the said investment in the same period of previous years (in Million of Tunisian dinar):

\begin{tabular}{|c|c|c|c|c|c|c|c|}
\hline & \multicolumn{4}{|l|}{ June } & \multicolumn{3}{|c|}{ Variation $2020(\%) /$} \\
\hline & 2017 & 2018 & $2019 * *$ & $2020 * *$ & 2019 & 2018 & 2017 \\
\hline Portfolio & 52,1 & 69,1 & 45,6 & 39,1 & $-14,3 \%$ & $-43,5 \%$ & $-25,0 \%$ \\
\hline FDI & 918,3 & 1072,9 & 1251,5 & 1074,1 & $-14,2 \%$ & $0,1 \%$ & $17,0 \%$ \\
\hline Energy & 495,1 & 526,0 & 490,0 & 445,8 & $-9,0 \%$ & $-15,3 \%$ & $-10,0 \%$ \\
\hline Industry & 331,4 & 403,2 & 664,9 & 576,5 & $-13,3 \%$ & $43 \%$ & $74,0 \%$ \\
\hline Services & 89,3 & 137,8 & 90,3 & 44,4 & $-50,8 \%$ & $-67,8 \%$ & $-50,3 \%$ \\
\hline Agriculture & 2,50 & 5,85 & 6,28 & 7,4 & $18,0 \%$ & $26,6 \%$ & $196,3 \%$ \\
\hline Total & 970,4 & 1142,0 & 1297,0 & 1113,2 & $-14,2 \%$ & $-2,5 \%$ & $14,7 \%$ \\
\hline
\end{tabular}

Source : FIPA, "Bilan de l'investissement étranger à la fin du premier semestre de l'année 2020 », Invest in Tunisia, August 2020.

Regarding the distribution of foreign investments by sector, Services were the sector that was most affected by this decline where investments reached 20.4 million dinars at the end of March 2020 while they amounted to 59 million dinars in the same period of the previous year. The second largest decrease concerns the industrial sector with a decline of $-21.5 \%$. The energy sector is also facing a fall in investments worth 53.2 million dinars, or $-18.6 \%$. Indeed, foreign investments in this sector dropped from 286.1 to 233 million dinars between March 2019 and March 2020. Particularly noteworthy is the fact that the agricultural sector recorded a spectacular increase in investments growing from 580,000 dinars at the end of March 2019 to nearly 4 million dinars in 2020.

Finally, it should be underlined that while the budgetary pressure, the difficult public finance situation and the decline in foreign direct investment continued to weigh heavily on the Tunisian economy at the start of 2020, both health and economy showed signs of resilience in the short term upstream of the COVID-19 crisis. 
Without a doubt, the period after the ordeal of the coronavirus is both uncertain and unpredictable in the one hand and a challenging time in the other; but for Tunisia, it will be an opportunity to reexamine its economic objectives with an eye towards emerging as a more focused and more resilient country. It is in this context that Tunisia is expected to head into a new era of «Building Back Better » with an emphasis on a number of fundamental changes combined short and medium- term actions:

\section{THE REFORMS UNDERTAKEN BY THE TUNISIAN STATE}

So far, Tunisian Government looks forward to emerge relevant key reforms and to carefully take actions for a more efficient and reinforced health system.

\subsection{A Leap Forward Digitalization}

Tunisia is making strides towards a further and faster digital transformation which is already at the heart of the strategies of most Tunisian institutions and enterprises. This is part of an ambitious digitalization plan launched before the corona crisis and which aim is to make the country an international benchmark in digital technology.

The unprecedented pandemic of Covid-19 is not without advantages for Tunisia. One thing that we already know is that this crisis is accelerating an already growing trend towards digitalization, as « It is in moments of crisis that a paradigm shift becomes most desirable ». From virtual meetings to automation, online orders to drone delivery, digital services are growing in importance in Tunisia which will permit an increasing number of sectors and activities.

It is in this context that the deployment of digital technologies could expand in Tunisia following the experiences during the pandemic. We are expecting for a vast reform of Tunisian administration, through the implementation, within a very short period of time, of a strategy for the digitalization of Tunisian organizations and essential public services to move at a faster pace from traditional ways of conducting business to the effectiveness in the one hand and to insulate themselves from future shocks in the other; Digital transformation is the keystone that requires changing internal processes and even the culture of the country as part of an overall strategy.

\subsection{Extensive Revolution in Research and Innovation}

Undoubtedly, the Covid-19 crisis served as a tipping point increasing the amount of research and innovation into ongoing development in advanced automation (Robots), additive manufacturing (3D printing) and Artificial Intelligence which will be among the main transformational engines of change and development in Tunisia.

The country has been lauded for its investments in these high-value segments that have been approved for use in Tunisia to support the Fight against Covid-19. The flurry of Quick-Reaction Innovations sparked during the era of coronavirus Crisis is letting Tunisia to join the innovation race and to improve its competitiveness globally.

This recent growing market we're seeing emerging and upswing in Tunisia will no doubt be taken to a level that have never been achieved before in Tunisia. The country has made a major leap towards the use of these knowledge-intensive sectors during this period of crisis and will make a far greater focus on their modernization to meet its goal of being Artificial Intelligence hub of Africa and the MENA and being part of a world where technology rules.

In order to reach these targets, it is crucial for Tunisian Government to- at best- encourage policy makers to take more measures to succeed in these new technological shifts which will definitely be a bigger part of Tunisia's future.

\section{How Can Tunisia Grow FDI LeVels Post Covid-19?}

With no doubt, Tunisia has all the necessary assets and capabilities to attract new foreign investment. In order to reconfirm its position as a reliable near shore destination, the country should think innovatively to generate investment results in a challenging environment. This could be by taking significant and highly ambitious strategic actions which areas of focus will include: 


\section{- A Proactive and Adjusted Communication Plan}

- Through the Establishment of a robust communication strategy that clearly highlights Tunisia's merits in terms of efficiency and performance as regards to its health and economic resilience, with an available evidence that FDIs motivations will depend greatly on the success of both these public health and economic policy responses ;

- Through the revision of the countries' value proposition by focusing on even more significant assets that will bring Tunisia's attractiveness out of the ordinary. Indeed, the communication strategy should spread awareness of the robustness and capabilities of Tunisian human capital operating in the fields of innovation and technology. This could be clearly laying out through a video or a reporting that highlights the attractiveness of Tunisian site and the genuity of its human capital, that could have important implications for FDIs flows.

This bold communication strategy requires a unified approach that engages effectively all the concerned Tunisian institutions and entities for a deployment of an aligned and harmonized investment promotion messages.

\subsection{An Investment in Technology and Infrastructure}

Potential investor's decision will vary greatly among countries depending on the entire facilities in logistical capabilities. Degradation or limited availability of core infrastructure such as mass transit, telecommunications and internet may pose further challenges to attract FDI from high-income countries. Thus, in the medium term (second half of 2020 and 2021), Tunisia, which logistic sector plays a vital role in its economy, should carefully improve the efficiency of its transport network in order to drive economic recovery after the pandemic and to deliver significant opportunities for future growth; and its digital infrastructure in order to allow firms operating remotely both along global value chains and in reaching out to foreign markets. Taken together, this could indicate that Tunisia is seeing the start of a global shaped recovery of business activity.

\subsection{A Shift in Target Strategic Sectors for Investment}

Tunisia is following in real time global trends pertaining to current status of sectors. For the country, certain sectors may become more strategic. Shifting them should be in line with its comparative advantages and with global market conditions and outlook. In line with this, Tunisian strategy needs to evolve and be aligned with broader efforts to promote international cooperation in these target sectors. So, the country could may adapt and maintain, perhaps even prematurely, its competitive edge.

\subsection{Redefinition of Geographical Ambitious}

In its investment attraction and generation strategy, Tunisia should take into consideration the decisions of multinational enterprises to reduce their dependence on Chinese manufacturing and shorten their supply chains through on shoring or near shoring some of their production activities.

Tunisia will be a strong contender to benefit from the opportunity offered by the Covid-19 crisis, thanks to its preferential and structural assets. Responding to this new possible configuration, restructuring promotional efforts are underway to reconfirm Tunisia's position as a reliable near shore destination especially for the EU markets. Furthermore, Tunisia think innovatively through an agile approach to attracting Asian investment within the global context, as Asia still has enormous competitive advantages for medium and high-tech production -and comprises the world's largest, most populous, and fastest growing market - so this will not be an exodus of investment but there will be more opportunities for Tunisia, with national security concerns driving this.

\subsection{Retention of Existing Investment}

After all, it should be borne in mind that the best way to grow FDI levels post-Covid-19 is to give support and care to existing investors. Focusing in both investment facilitation and aftercare while at the same time understanding the evolving needs of investors is the major policy approach adopted by Tunisia since the beginning of the COVID-19 outbreak, particularly by the Foreign Investment Promotion Agency «FIPA Tunisia » responsible for attracting investment to Tunisia, with a view towards increasing the embeddedness of existing investment within Tunisian economy and thus expanding their projects. 


\section{Which Sectors of THE TUNISIAN ECONOMY SHOULd InVESTORS BE LOOKING AT IN THE AFTERMATH OF COVID-19}

Tunisia is following the different trends related to current status of sectors on the international level. For the country, a focus on selected strategic sectors with more digital industries, automotive components, pharmaceutical and agriculture is at the forefront of Tunisia's promotional strategy:

- The Digital Sector is the new spearhead of the Tunisian economy. It has recorded a significant and continuous growth during the last years. It accounts for 7.5 percent of GDP and provides jobs to 80,000 people in roughly 1,800 companies, more than 500 of which are considered to be in promising sectors such as AI, IoT, Blockchain, Big Data, and Fin Tech.

Its good education system is an asset for Tunisia: 60,000 students graduate from Tunisian universities every year, among them roughly 9,000 in IT related majors and 6,000 engineers. Their wages are competitive and the broadband infrastructure in Tunisia counts among the most modern in the Mediterranean region with high-speed Internet and an international connectivity rate of $810 \mathrm{~Gb} / \mathrm{s}$.

Tunisia's government has devised its national strategy Tunisie Digitale 2018/2020 to support investments by private-sector enterprises and to advance digital transformation throughout the country. It promotes Tunisia as an IT hub for Europe, Africa, and the Middle East offering a diversified and cross-sector investment incentive system. Digital sector in Tunisia was expected to attract high value investments in the aftermath of Covid-19. This is due to its business dynamism, strong institutional pillars, financing mechanisms and vibrant innovation ecosystem. For foreign investors, digitalization has a profound influence on their investment decisions as it will provide them holistic solution for access to markets as well as for investment opportunities.

- The Automotive Components Sector is quite developed. Tunisia is indeed the 3rd car components manufacturer in Africa. The country has been able to build up a very good local supply industry with the presence of a number of foreign companies such as Kromberg \& Schubert, Autoliv, Dräexlmaier, Yazaki, Sumitomo and valéo who have chosen Tunisia to supply car manufacturers like Audi, VW, Renault, Volvo, Ford mainly with wire harnesses, electronic and electrical components and plastic parts...

With the global economy shaken by the coronavirus outbreak, Tunisia could become more attractive than ever. It is well-positioned to take advantage of the revival of the European automotive industry, as it will benefit from the restructuring efforts of Equipment Manufacturers who will consider the concentration of all production in Asia as a risk and will regionalize parts of their value chain.

Car manufacturers will want to get as close as possible to their markets, but will take into account the situation that the new coronavirus has imposed on them. For Tunisia, this would represent a major growth driver after covid-19, a country with industry built on an export model (more than 65 percent of vehicles destined for Europe), with generous incentives and policies that support investment, a specialized efficient pool of talents and an industrial infrastructure geared towards value creation.

\section{- Pharmaceutical Industry}

Tunisia was the first country to develop the pharmaceutical industry in Africa. According to a recent Harvard Business Review study, Tunisia has the most complex industrial state in Africa and according to Bloomberg's one of the 60 most innovative countries in the world.

In the era of Covid-19 crisis, health has now become a broader question of security and current EU dependency on China offers a unique opportunity for Europe pharmaceutical companies to rethink relations with neighbors in North Africa. With an ongoing shortage of medical products masks, gloves, swabs, health has become a question of sovereignty and security.

Tunisia is well placed to benefit from these European considerations. A good standard of education, proximity with Europe and centuries old links of trade, argue in its favor. Moreover, the EU and its leading states, notably France, Spain and Italy have a vested interest in the stability of the western and central Mediterranean. They know that production costs in Tunisia are way below those of the EU, probably above those of China.

- Agriculture is a key sector of the Tunisian economy, accounting around 1088 companies of which more than 120 are foreigners and employing 75000 of the workforces. An improvement in production 
methods in the past years has allowed the sector to have a world leadership position in the organic dates and olive oil segments, while enabling the country to reach a level of food sufficiency. Additionally, organic farming is also booming, with $95 \%$ potential for converting hectares of olive groves into organic farming, even for BIO as Tunisia is one of the most productive countries in Africa and 1 st Country with recognition of the BIO EU equivalence.

Despite the fact that the agriculture is little affected by COVID-19 pandemic, Tunisia should preserve this vital sector with particular emphasis on the grain industry, relying on the real resources and productive capacity of the country, while it is important to make preventative investments in this sector for a resilient and adaptative economic recovery.

\section{REFERENCES}

[1] Ben Mohamed D. (2020), «Innovation at the heart of the Covid-19, Crisis in Tunisia », Oxford Business Group, Le Point Afrique.

[2] FIPA, “ Bilan de l'investissement étranger à la fin du premier semestre de l'année 2020 », Invest in Tunisia, August 2020.

[3] Jawad R. and Smith-Walters M. (2020), "Coronavirus: The students that are printing PPE masks in Tunisia", BBC News, Africa.

[4] Kuo R. (2020), "Real-Time FDI Project Announcement Trends", Connor Huang FDI 2020 TRENDS, World Bank Group, Finance, competitiveness and Innovation.

[5] LADEPECHE.fr (2020), "En Tunisie, intelligence artificielle et robots face au virus », April 2020.

[6] O’Donovan D. and Sawaqed L. (2020), "Investment Policy and Promotion", FIPA CAPACITY BUILDING WORKSHOP: INVESTOR AFTERCARE, World Bank Group, June 29 - July 2

\section{AUTHORS' BIOGRAPHY}

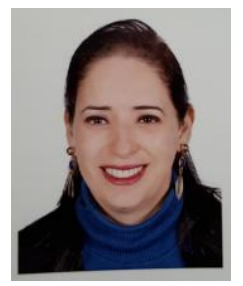

Syrine Ben Romdhane holds a Doctorate in Management Sciences from the Faculty of Economics and Management of Tunis. The author is currently Assistant Professor at the Higher Institute of Management of Tunis where she teaches Financial Management, Portfolio Management, Financial Mathematics, Advanced Financial Analysis and Financial Diagnosis. The author also provides supervision for students enrolled in a Research Master or a Professional Master. She has published research articles in reputable journals and wrote a book entitled "Impact of Information Technologies on Banking Performance", European University Editions. She taught Finance courses also in private institutes (ULT University, Time University, Central University and ESPRIT)

Citation: Syrine Ben Romdhane. “Economic Situation in Tunisia and Resilience Strategies in Times of Covid19 and Beyond "International Journal of Managerial Studies and Research (IJMSR), vol 8, no. 10, 2020, pp. 17-23. doi: https://doi.org/10.20431/2349-0349.0810003.

Copyright: (C) 2020 Authors. This is an open-access article distributed under the terms of the Creative Commons Attribution License, which permits unrestricted use, distribution, and reproduction in any medium, provided the original author and source are credited. 